\title{
Article \\ The Development of a Flight Test Platform to Study the Body Freedom Flutter of BWB Flying Wings
}

\author{
Pengtao Shi, Feng Liu, Yingsong Gu*D and Zhichun Yang \\ School of Aeronautics, Northwestern Polytechnical University, Xi'an 710072, China; spt@mail.nwpu.edu.cn (P.S.); \\ liu_feng@mail.nwpu.edu.cn (F.L.); yangzc@nwpu.edu.cn (Z.Y.) \\ * Correspondence: guyingsong@nwpu.edu.cn
}

check for updates

Citation: Shi, P.; Liu, F.; Gu, Y.; Yang, Z. The Development of a Flight Test Platform to Study the Body Freedom Flutter of BWB Flying Wings. Aerospace 2021, 8, 390. https:// doi.org/10.3390/aerospace 8120390

Academic Editors: Bosko Rasuo and Rosario Pecora

Received: 14 September 2021

Accepted: 8 December 2021

Published: 10 December 2021

Publisher's Note: MDPI stays neutral with regard to jurisdictional claims in published maps and institutional affiliations.

Copyright: (c) 2021 by the authors. Licensee MDPI, Basel, Switzerland. This article is an open access article distributed under the terms and conditions of the Creative Commons Attribution (CC BY) license (https:/ / creativecommons.org/licenses/by/ $4.0 /)$.

\begin{abstract}
A flight test platform is designed to conduct an experimental study on the body freedom flutter of a BWB flying wing, and a flight test is performed by using the proposed platform. A finite element model of structural dynamics is built, and unsteady aerodynamics and aeroelastic characteristics of the flying wing are analyzed by the doublet lattice method and g-method, respectively. Based on the foregoing analyses, a low-cost and low-risk flying-wing test platform is designed and manufactured. Then, the ground vibration test is implemented, and according to its results, the structural dynamics model is updated. The flight test campaign shows that the body freedom flutter occurs at low flight speed, which is consistent with the updated analytical result. Finally, an active flutter suppression controller is designed using a genetic algorithm for the developed flying wing for future tests, considering the gains and sensor location as design parameters. The openand closed-loop analyses in time- and frequency-domain analyses demonstrate that the designed controller can improve the instability boundary of the closed-loop system effectively.
\end{abstract}

Keywords: body freedom flutter; ground vibration test; flight test; active flutter suppression design

\section{Introduction}

Compared with conventional aircraft, flying wings have a higher lift-drag ratio and better stealth capability [1,2], which have become a research hotspot of advanced aircraft in recent years [3]. The flying wings generally have a large aspect ratio to meet the requirements of high altitude and long endurance, leading to increased flexibility and decreased elastic modal frequency of the wing. As a result, a special aeroelastic phenomenon occurs, known as body freedom flutter (BFF), caused by the coupling between the low order wing bending mode and the rigid body pitching mode. BFF badly affects the handling performance and even leads to the disintegration of flying wings [4,5]. Due to the particularity of the flutter, aeroelastic analyses are very important during the aircraft design process [6], by which we can determine the flutter characteristics and check if the performance of the vehicle meets the design requirements.

The studies on aeroelastic characteristics of flying wings include the flutter mechanism investigation $[7,8]$, passive flutter suppression $[9,10]$, and active flutter suppression (AFS) [11,12]. Some of the studies only focus on the theoretical analyses of the BFF $[9,10,13,14]$. The experimental studies on flying wings such as the ground vibration test (GVT) [15], wind tunnel test [16,17], and flight test [18,19] have made significant signs of progress recently. Zhao et al. [15] introduced an optimization method for composite flying-wing finite element model (FEM) updating based on subcomponent test data. The FEM method is updated according to the GVT and optimization algorithm, agreeing with the test model well. Gu et al. [16] and Liu et al. [17] both carried out wind tunnel test studies on BFF. Liu et al. [17] pointed out that for the flying wing with two-points elastic support, the flutter characteristics obtained from the BFF wind tunnel test will be affected by the support stiffness of spring. Zhang et al. [18] and Wu et al. [19], respectively, using numerical simulation and wind tunnel tests, proved that the support system will interfere 
with the wind tunnel test results and cannot accurately simulate the actual flight state. Therefore, it is necessary to carry out a flight test to study the BFF of flying wings.

As for the flight test study of BFF, Schmidt et al. [11,12] focused on the study of BFF suppression of flying wings, and the closed-loop flight test for different flutter active suppression controllers was completed. It should be noted that the vehicle may be damaged during a flutter flight test, which even causes secondary disasters (the fragment of the vehicle may fall and hurt people after disintegrating). Therefore, it is necessary to develop a low-cost and low-risk (LCLR) flying wing as a flight test platform for the study of BFF.

In previous research, there have been scarce studies on the BFF flight test, and there is almost no study to systematically introduce the detailed development process of the BFF flight test platform. In this paper, the design and test processes of an LCLR flying wing as a flight test and research platform for BFF are investigated in detail. The unsteady aerodynamic, structural dynamic, and aeroelastic characteristics of the designed flying wing are analyzed by the doublet lattice method (DLM), finite element (FE) method, and g-method, respectively. The GVT is conducted to update the analytical model, and the flight test is performed to observe the phenomena of BFF. For the developed flying wing, an AFS controller is established, and the flutter suppression effect of the controller is verified by time- and frequency-domain analyses.

\section{Theoretical Fundamentals}

\subsection{Doublet Lattice Method}

For harmonic oscillation, the linear small disturbance velocity potential equation is

$$
\left(1-M a_{\infty}^{2}\right) \frac{\partial^{2} \varphi}{\partial^{2} x}+\frac{\partial^{2} \varphi}{\partial^{2} y}+\frac{\partial^{2} \varphi}{\partial^{2} z}-2 i\left(\frac{M a_{\infty}^{2} k}{b}\right) \frac{\partial \varphi}{\partial x}+\frac{M a_{\infty}^{2} k^{2}}{b^{2}} \varphi=0
$$

where $k=b \omega / V$ is the reduced frequency, $b$ is the reference length, and $\omega$ is the circular frequency, respectively.

DLM [20] is a panel method based on the linear velocity potential equation of small disturbance, which is used for unsteady aerodynamics analysis in this paper, and the lifting surface is divided into a number of aerodynamic grids, as shown in Figure 1. The positive direction of the $x$-axis is consistent with the far-field flow direction, the $y$-axis is pointing to the right, and the $z$-axis is determined according to the right-hand rule. The aerodynamic force acts at the midpoint of the $1 / 4$ chord line on each grid element, which is called the pressure point $\left(F_{2}\right)$, and the midpoint of the $3 / 4$ chord line is called the downwash control point $(H)$. The boundary conditions at the control points of each grid are met due to the amplitude of the normal downwash velocity generated by the proper doublet line distribution.

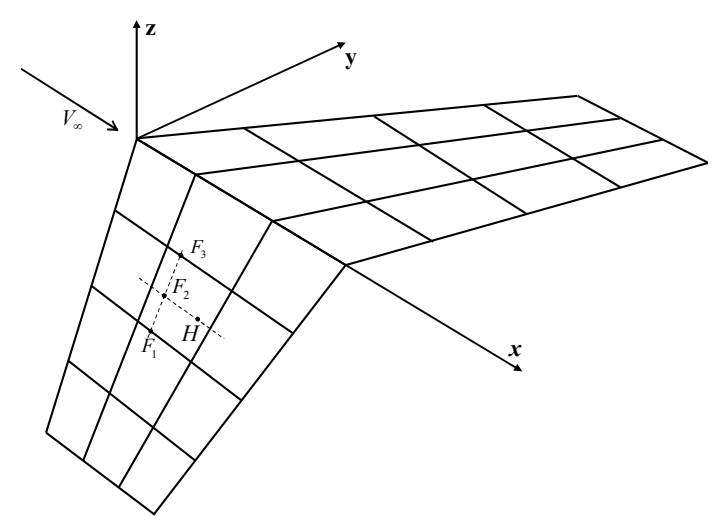

Figure 1. Sketch of grid division used in DLM.

It is assumed that the lifting surface is divided into $n$ grids, and the pressure difference $\Delta p$ on each grid is constant; pressure doublets are arranged at the points of each grid. 
Based on the theory of linear unsteady aerodynamics, the integral equation is satisfied at the downwash control point of each aerodynamic grid as follows:

$$
\begin{aligned}
w_{i} & =\frac{1}{4 \pi \rho V^{2}} \sum_{j=1}^{n} \frac{1}{2} \rho V^{2} \Delta c_{p_{j}} \Delta x_{j} \cos \phi_{j} \int_{l_{j}} K_{i j} d l_{j} \\
& =\frac{1}{8 \pi} \sum_{j=1}^{n} \Delta c_{p_{j}} \Delta x_{j} \cos \phi_{j} \int_{l_{j}} K_{i j} d l_{j} \quad(i=1,2, \ldots, n ; j=1,2, \ldots, n)
\end{aligned}
$$

where $w_{i}$-the downwash at the $3 / 4$ chord length point of the $i$ th grid; $\Delta c_{p_{j}}$-the pressure coefficient on the $j$ th grid; $\Delta x_{j}$ - midsection length of the $j$ th grid; $l_{j}$-length at $1 / 4$ chord $\overline{F_{1} F_{3}}$ of the $j$ th grid; $\phi_{j}$-sweepback angle at $1 / 4$ chord $\overline{F_{1} F_{3}}$ of the $j$ th grid; $K_{i j}$-aerodynamic kernel function.

The unsteady aerodynamic pressure distribution at the pressure point is written in matrix form as

$$
\Delta \mathbf{p}=\frac{1}{2} \rho V^{2} \mathbf{D}^{-1} \mathbf{w}
$$

where $\Delta \mathbf{p}$-pressure distribution vector at the point of pressure action; $\mathbf{w}$ - the downwash vector at the downwash control point; $\mathrm{D}$ - the aerodynamic influence coefficient matrix.

By applying the modal approach, the generalized aerodynamic forces matrix can be written as

$$
\mathbf{Q}(i k)=\boldsymbol{\Phi}^{T} \mathbf{G}^{T} \mathbf{D G} \boldsymbol{\Phi}
$$

where $\mathbf{G}$ is the spline matrix, and $\boldsymbol{\Phi}$ is the modal matrix.

Up to now, the unsteady aerodynamic force is calculated by DLM, and the generalized aerodynamic force matric used for aeroelastic analysis is obtained. In addition, it should be noted that when the reduced frequency $k=0$, DLM degenerates into the vortex lattice method (VLM), which is used for steady aerodynamic analysis in the next section.

\subsection{The g-Method}

The $g$-method is used for aeroelastic characteristics analyses in this paper. The flutter solution equation of the g-method $[21,22]$ is

$$
\left[\left(V^{2} / b^{2}\right) \mathbf{M} p^{2}+\mathbf{K}-\frac{1}{2} \rho V^{2} \mathbf{Q}^{\prime}(\mathrm{i} k) g-\frac{1}{2} \rho V^{2} \mathbf{Q}(\mathrm{i} k)\right]\{\mathbf{q}\}=0
$$

where $\mathbf{M}, \mathbf{K}$, and $\mathbf{Q}(i k)$ are the generalized mass, generalized stiffness, and generalized aerodynamic force, respectively. The relationship between the reference length $b$ and the reference chord length $c$ is $b=c / 2$.

Substituting the dimensionless operator $p(p=g+\mathrm{i} k)$ into Equation (5), we can obtain a second-order linear system with respect to $g$

$$
\left[g^{2} \mathbf{A}+g \mathbf{B}+\mathbf{C}\right]\{\mathbf{q}\}=0
$$

where $\mathbf{A}=(V / L)^{2} \mathbf{M} . \mathbf{B}=2 i k(V / L)^{2} \mathbf{M}-\frac{1}{2} \rho V^{2} \mathbf{Q}^{\prime}(i k)+(V / L) \mathbf{Z} . \mathbf{C}=-k^{2}(V / L)^{2} \mathbf{M}+$ $\mathbf{K}-\frac{1}{2} \rho V^{2} \mathbf{Q}(i k)+i k(V / L) \mathbf{Z}$.

For completeness, the modal damping matrix $\boldsymbol{Z}$ is included in Equation (6). To satisfy the condition for the existence of solutions, Equation (6) is written in the state space form

$$
[\mathbf{D}-g \mathbf{I}]\{\mathbf{X}\}=0
$$

where $\mathbf{D}=\left[\begin{array}{cc}0 & \mathbf{I} \\ -\mathbf{A}^{-1} \mathbf{C} & -\mathbf{A}^{-1} \mathbf{B}\end{array}\right]$ and $\{\mathbf{X}\}$ is the right eigenvector of the state space equation.

A reduced-frequency-sweep method is used to search the condition of $\operatorname{Im}(g)=0$ and solve the eigenvalues of D. By changing the reduced frequency $k$ with a step $\Delta k$, the one for $\operatorname{Im}(g)=0$ is obtained by linear interpolation when the imaginary part symbols 
of the eigenvalues correspond to $k$, and $|k+\Delta k|$ changes from negative to positive. Then, the flutter frequency is calculated by $\omega_{f}=k(V / L)$, and the damping is calculated by $2 \gamma=2[\operatorname{Re}(g) / k]$ when $k=0$, there is $2 \gamma=\frac{\operatorname{Re}(g)(L / V)}{\ln (2)}$.

\section{Configuration Design of the BFF Flight Test Platform}

\subsection{Aerodynamic Configuration}

The BWB aerodynamic configuration of the designed flying wing is shown in Figure 2. It is a high-aspect-ratio flying wing, of which the wingspan and aspect ratio is $2 \mathrm{~m}$ and 10.2, respectively.

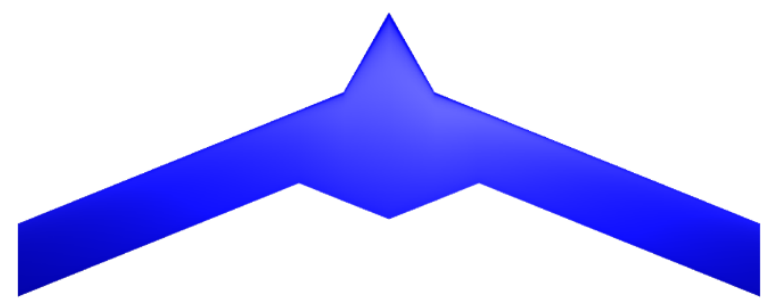

Figure 2. Aerodynamic configuration of the flying wing for BFF flight test platform.

The steady aerodynamic characteristics of the flying wing were estimated by using XFLR5, a tool for wing design and analysis based on the VLM method. By setting the gravity center to $0.38 \mathrm{~m}$ aft the nose, the resulting lift and pitching moment coefficients of the flying wing versus with the angle of attack are shown in Figure $3 a, b$, respectively. From Figure $3 b$, we can see that the slope of the pitch moment coefficient is negative, indicating that the flying wing has a sound static longitudinal stability. This means that the aircraft will be easy to operate, which is a key factor for the successful implementation of the flight test. In brief, the flying wing has good aerodynamic characteristics.
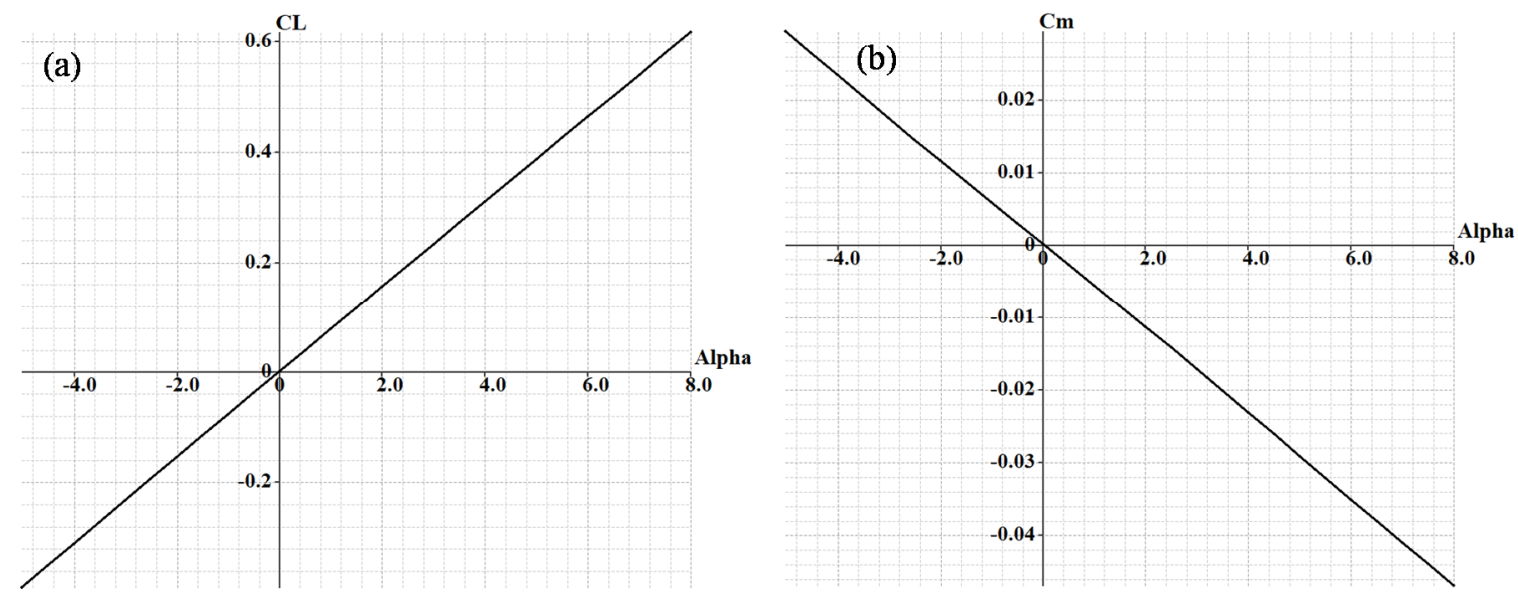

Figure 3. Coefficients of (a) lift and (b) pitching moment versus with angle of attack (with Alpha in degrees).

\subsection{Structural Configuration}

The structural configuration of the flying wing was established based on the aerodynamic analyses, as shown in Figure 4. The flying wing test platform was an unmanned aerial vehicle (UAV) equipped with commercial flight control and power systems. The spar was made of carbon-fiber-reinforced composite material (CFRCM), and the lifting surface was made of the polypropylene (PP) foam board, partially reinforced by balsa wood. The study of Gavrilovic et al. [23] shows that the winglet can significantly improve the lift-drag ratio of the aircraft. In order to improve the performance of the flying wing, we added the winglet to improve the lift drag ratio and the lateral heading stability. 


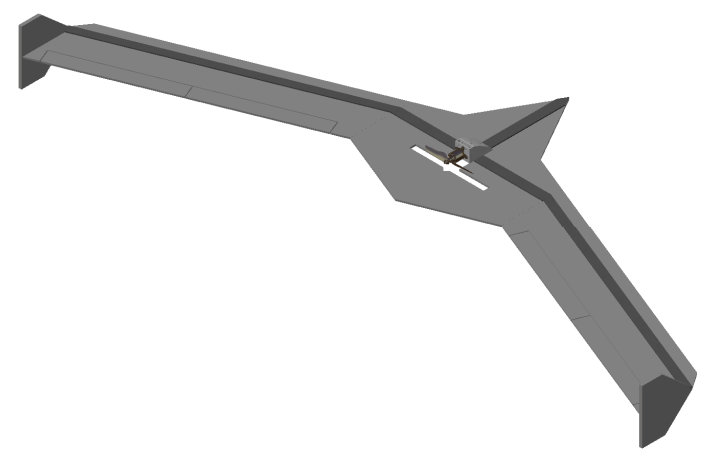

Figure 4. Structural configuration of flying wing for BFF flight test platform.

The designed configuration satisfies the necessity of LCLR and meets the flight test requirements, specifically in the following aspects: (1) the simple configuration is convenient for stiffness design, which means that we can ensure the flutter speed low enough for flight test safety; (2) the motor-driven propeller provides the thrust, which is highly efficient in low-altitude and low-speed conditions, and the propeller was installed in the waist of the vehicle, an arrangement that can protect people from injury by the blade; (3) the PP foam board, as a kind of flexible lightweight foam material, is easy to process. Considering the possibility of crash or disintegration caused by flutter during flight tests, using the PP foam board as the main material of lifting surface can effectively reduce the possibility of secondary damage and protect the equipment; (4) the flying wing compatible with the mature reliable commercial flight control system and power system, which can significantly save the cost and time of the design.

\section{Modeling and Analyses}

\subsection{Structural Dynamics}

In order to study the structural dynamic characteristics of the flying wing, a FEM model was established by using MSC.Patran, as shown in Figure 5. In this FEM, thin-shell element in MSC.Nastran was used to model the composite spar (purple), lifting surface (light blue), inner flap (red), outer aileron (green), and winglet (dark blue), and the airborne equipment was simplified as concentrated mass elements; the detailed information of the FEM model are summarized in Table 1. Considering the slenderness of the spar, it is reasonable to simplify CFRCM as an isotropic material, and the tensile modulus $E_{11}$ of the CFRCM was used as Young's modulus of the simplified isotropic material, which was $150 \mathrm{GPa}$, and the Poisson's ratio and density were 0.26 and $1600 \mathrm{~kg} / \mathrm{m}^{3}$, respectively. While Young's modulus, Poisson's ratio, and density of the material used by the lifting surface were $10 \mathrm{MPa}, 0.09$, and $20 \mathrm{~kg} / \mathrm{m}^{3}$, respectively.

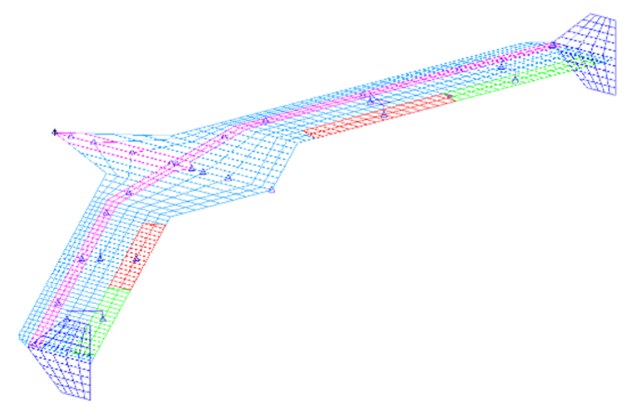

Figure 5. FEM of flying wing for BFF flight test platform. 
Table 1. Detailed information of FEM.

\begin{tabular}{cc}
\hline Type & Number \\
\hline CBAR & 12 \\
CONM2 & 17 \\
CQUAD4 & 998 \\
CTRIA3 & 12 \\
GRID & 1220 \\
\hline
\end{tabular}

Based on the FEM model, the normal mode analysis of the full span flying wing with a free-free boundary condition was carried out by MSC.Nastran. The frequencies of the first four elastic modes (corresponding to the 7th-10th modes under the free-free boundary condition, since the first six modes were rigid modes) are summarized in Table 2, and the corresponding mode shapes are shown in Figure 6.

Table 2. Frequencies and mode shapes of the first four elastic modes.

\begin{tabular}{ccc}
\hline Modal Order & Mode Shape & Modal Frequency (Hz) \\
\hline 7 & Symmetric 1st wing bending & 3.60 \\
8 & Antisymmetric 1st wing bending & 5.79 \\
9 & Symmetric 2nd wing bending & 8.63 \\
10 & Antisymmetric 2nd wing bending & 9.92 \\
\hline
\end{tabular}

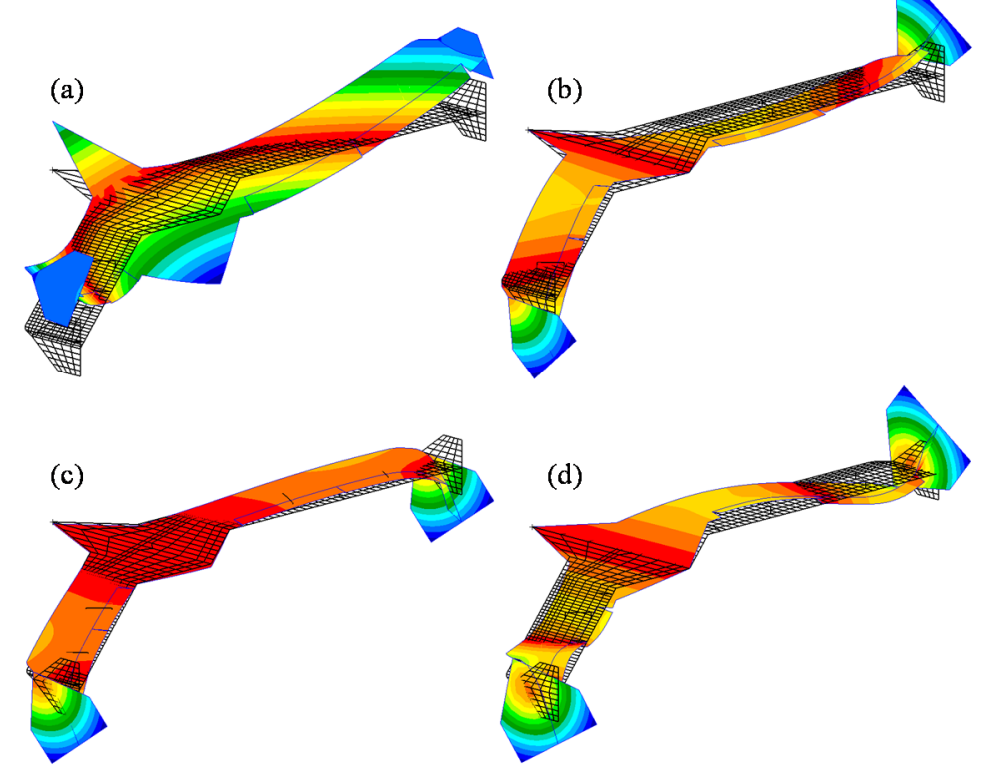

Figure 6. Mode shapes of first four elastic modes: (a) symmetric 1st wing bending; (b) antisymmetric 1st wing bending; (c) symmetric 2nd wing bending; (d) antisymmetric 2nd wing bending.

\subsection{Aeroelastic Modeling and Analysis}

In order to study the flutter characteristics of the flying wing, it was necessary to carry out an aeroelastic analysis. The lifting surface model of the full span flying wing corresponding to the structural FEM was established, as shown in Figure 7. The lifting surface was divided into 784 grids, and the corresponding aerodynamic influence coefficient matrix was calculated by DLM. 


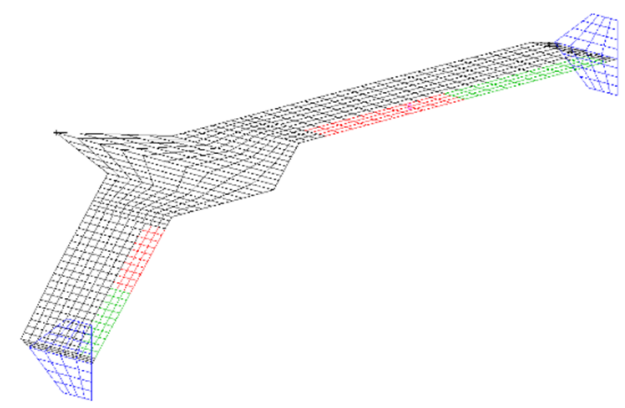

Figure 7. Lifting surface model of flying wing for BFF flight test platform.

Infinite plate spline interpolation was used between the lifting surface model and the structural FEM, then the aeroelastic model was obtained. The interpolated mode shapes of the aerodynamic meshes were checked, as shown in Figure 8. It can be seen that the interpolated mode shapes are in good agreement with the structural mode shapes shown in Figure 6, indicating the correctness of the aeroelastic model.

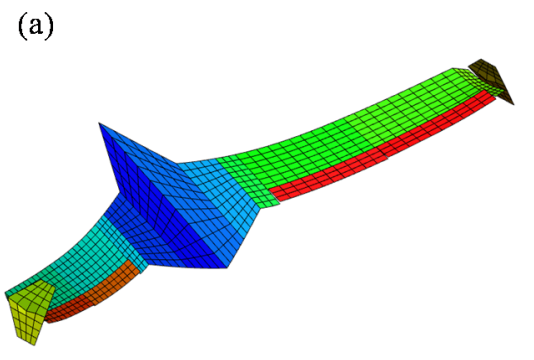

(c)

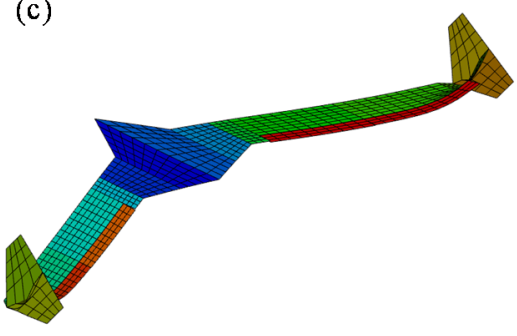

(b)

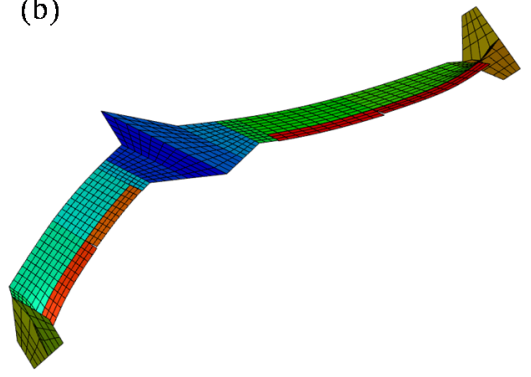

(d)

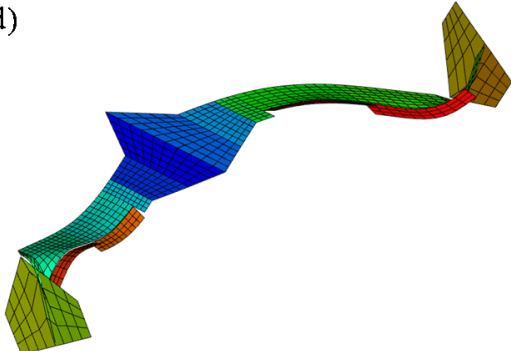

Figure 8. Interpolated mode shapes of aerodynamic mesh: (a) symmetric 1st wing bending; (b) antisymmetric 1st wing bending; (c) symmetric 2nd wing bending; (d) antisymmetric 2nd wing bending.

Then, the flutter analysis was carried out using the g-method; the rigid pitching mode and the first four elastic modes were selected for the analysis. The flight altitude was selected as sea level, and the Mach number was 0.04. The aeroelastic characteristics of the flying wing obtained by the g-method are shown in Figure 9, and only the rigid pitching and symmetric 1st wing bending modes are plotted for ease of observation. Results show that the aeroelastic instability occurs at the speed of $18.18 \mathrm{~m} / \mathrm{s}$, and the coupling between the rigid and symmetric 1st wing bending modes can be seen clearly, indicating that a typical BFF occurs. 

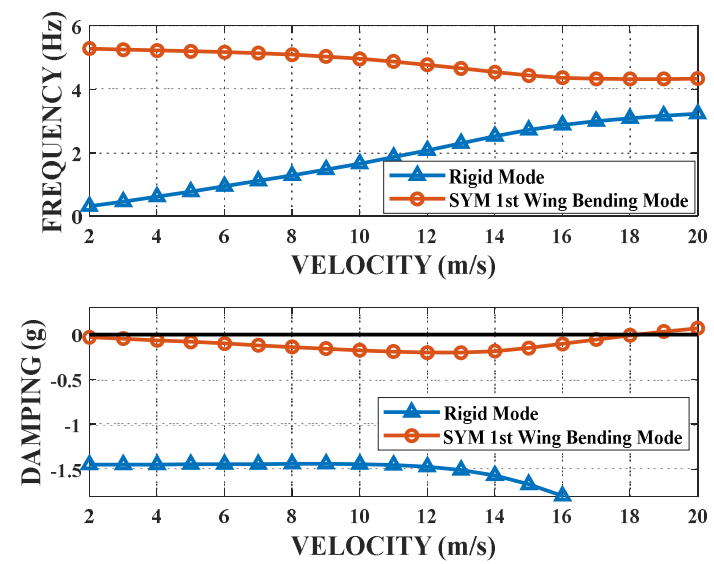

Figure 9. Aeroelastic analysis results.

\section{Ground Vibration Test}

\subsection{Introduction of Test Model}

Based on the foregoing analyses, the manufacturing and assembly of the flying wing were completed. The wing spar and lifting surfaces were bonded by adhesive. The winglets were glued with the wings, the control surfaces were connected with the wings by sets of hinges, and the fiber-reinforced tape was used to fill the gaps between the control surfaces and the wings. In order to improve the reliability of the propulsion system, balsa wood was used to strengthen the connection between the wing surface and the motor base. Two sets of overlapped CFRCM sheets tightened with bolts were used to connect the wing spar and the fuselage carried through the beam. The assembly details of the test model are shown in Figure 10.

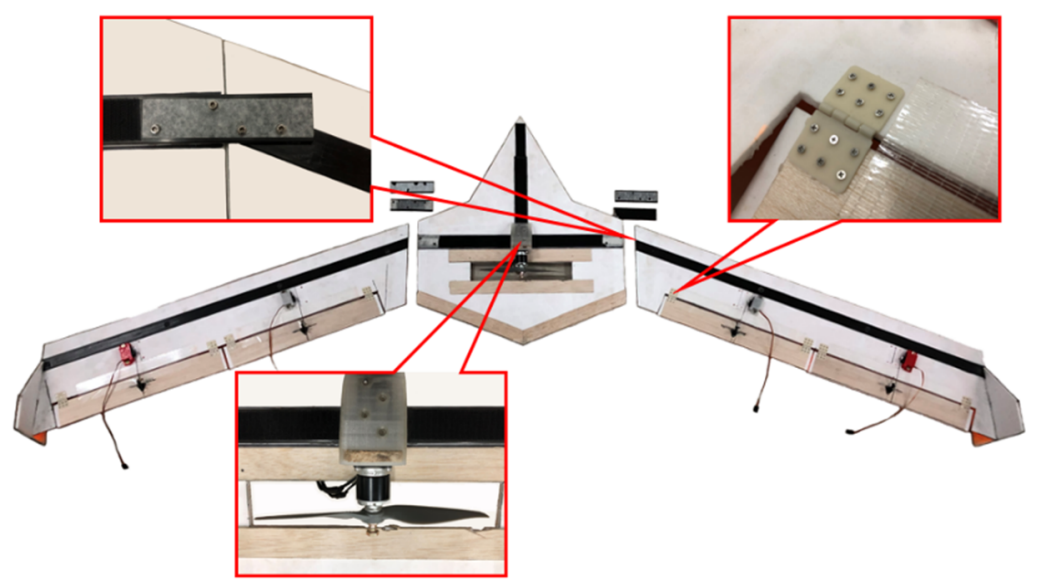

Figure 10. Assembly details of test model.

Then, the installation of airborne equipment was carried out. The assembled test model, including the airborne equipment, is shown in Figure 11. The flying wing used the commercial pix hawk flight control system, a global positioning system (GPS), digital data transmission (DDT), etc. It was driven by an ECO2316 motor with an APC 9-inch high-speed nylon blade. 


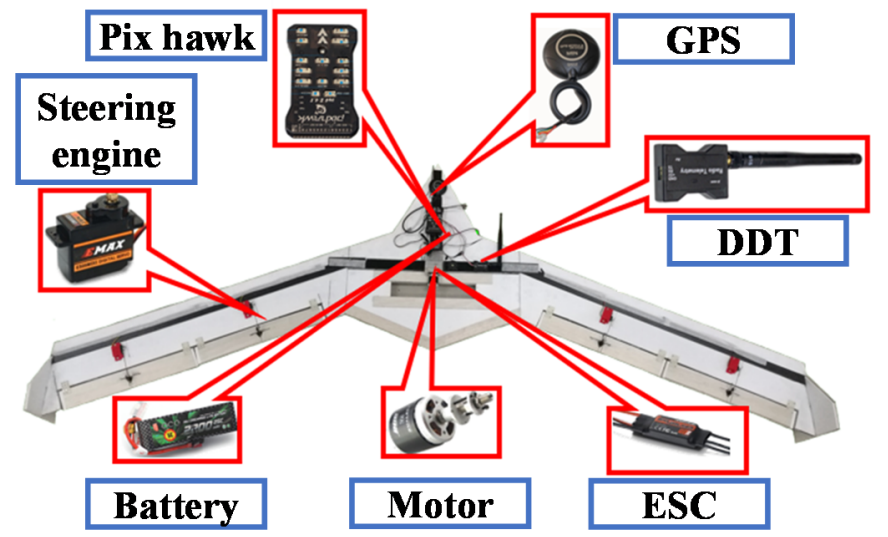

Figure 11. Test model including airborne equipment.

The detailed parameters of the test model are summarized in Table 3. The total weight of the test model with all airborne equipment was very light (only $1.3 \mathrm{~kg}$ ). When the motor was powered by the ACE $3 S$ battery, its maximum speed was RPM. The maximum thrust of this model could reach $13.86 \mathrm{~N}$, which exceeded the gravity of the fully assembled test model; that is, the maximum thrust-weight ratio of the test model was larger than 1. Consequently, the critical velocity of BFF could be easily realized during the flight test, which means that this platform was suitable for the flight test.

Table 3. Detailed parameters of the test model.

\begin{tabular}{cc}
\hline Items & Value \\
\hline Total weight $/ \mathrm{kg}$ & 1.3 \\
C.G.(from nose) $/ \mathrm{m}$ & 0.38 \\
Area of lifting surface $/ \mathrm{m}^{2}$ & 0.47 \\
Wingspan $/ \mathrm{mm}$ & 2024 \\
Aspect ratio & 10.2 \\
Sweepback/deg & 22 \\
\hline
\end{tabular}

\subsection{Tests and Results}

In order to identify the structural dynamic characteristics of the test model, a GVT test was carried out using the hammer impact method. The FE simulation results indicate that the first four elastic modes of the flying wing mainly manifest in the bending of the wing. Therefore, ten accelerometers were used to measure the acceleration signals, with eight of them arranged along the spanwise direction of the wing spar and two of them situated at the nose and tail, respectively. The layout scheme of the accelerometers, represented by the red dots, is shown in Figure 12.

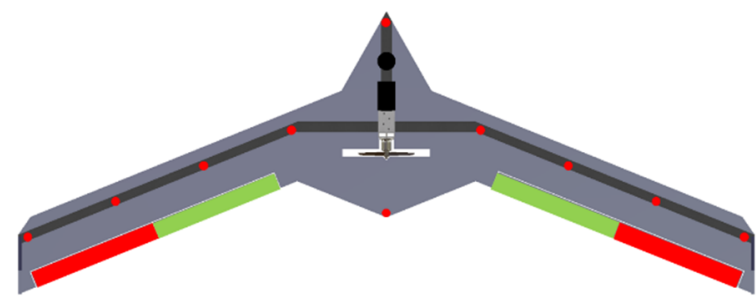

Figure 12. Layout scheme of sensors.

The setup of the GVT test is shown in Figure 13. The test model was hung on a rigid frame by a single-point spring suspension to simulate the free-free boundary condition. As the first four elastic modes of the flying wing were mainly represented by the bending of the wing, the excitation position of the impact hammer was selected at the wingtip. 
The accelerometers were glued to the corresponding locations, shown in Figure 11, and were connected to the data acquisition instrument of the LMS test lab system by cables. They measured the vibration signals generated by the striking of the impact hammer and transfer the signals to the LMS for data processing. Skillfully, the cables connected to the accelerometers and LMS were hung on the rigid frame loosely to reduce the test error caused by their self-weight.

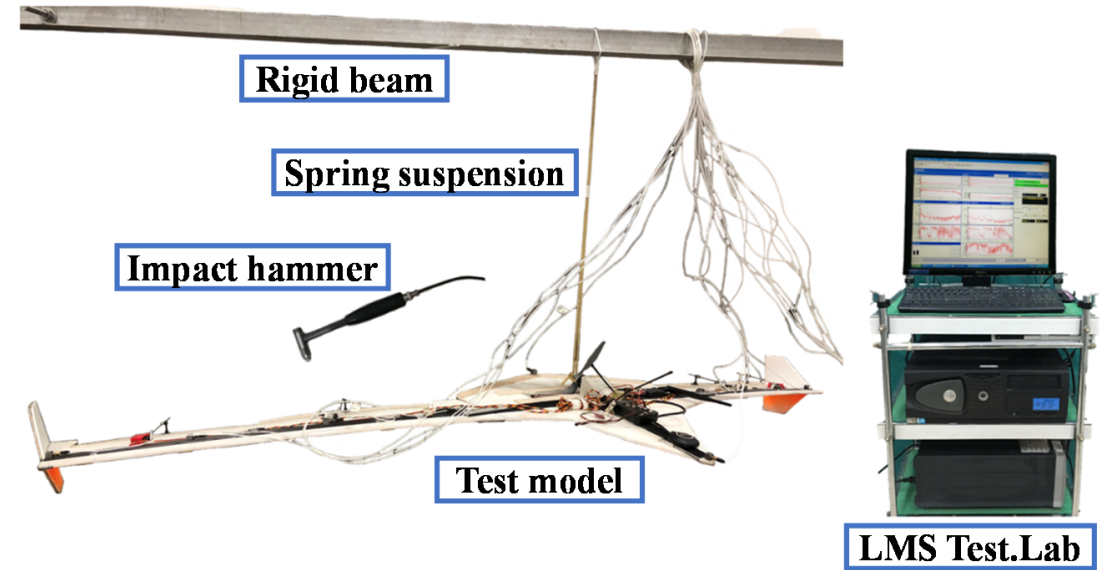

Figure 13. GVT setup.

The mode shapes of the first four elastic modes of the test model identified by the GVT simulation are shown in Figure 14. Since the ideal free boundary condition could not be realized by the single-point spring suspension, the elastic heaving mode (not the free-free one), i.e., the vertical elastic mode caused by the spring suspension, did not exist in the analysis model but could be obtained by the GVT test. Meanwhile, caused by the arrangement of accelerometers, the torsional mode of the wing could not be measured, and the fuselage bending of the symmetric first wing bending was also hardly excited by the wingtip excitation. The mode shapes did not match so well for the fuselage bending and wingtip mode between GVT and FEM simulations. However, the wing bending modes that we were chiefly concerned about matched well between the GVT and FEM simulations.

(a)

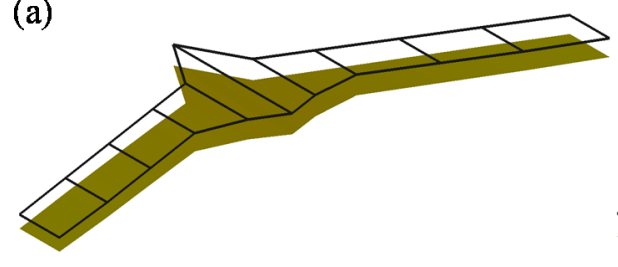

(c)

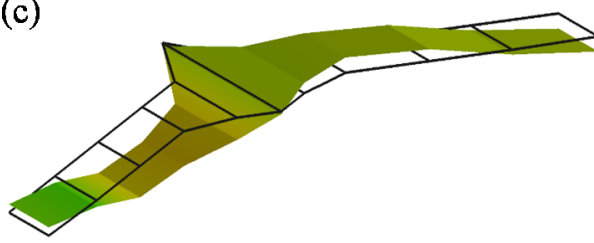

(b)

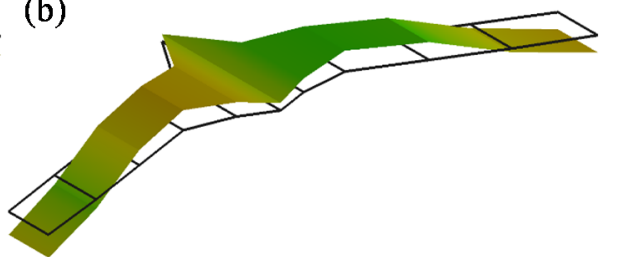

(d)

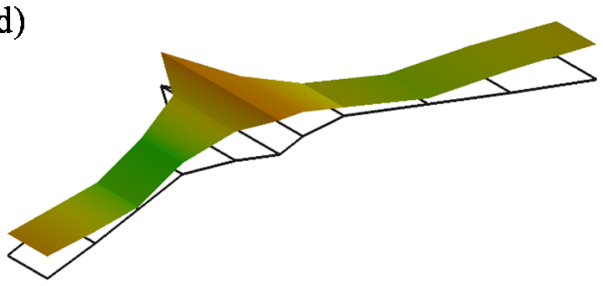

Figure 14. Mode shapes of first four elastic modes obtained from GVT: (a) elastic heaving; (b) symmetric 1st wing bending; (c) antisymmetric 1st wing bending; (d) symmetric 2 nd wing bending.

The first four elastic modal frequencies obtained from GVT are summarized in Table 4. The test model with light weight was very sensitive to mass distribution. Therefore, the test results change with the layout schemes of the accelerometers. In order to further reduce the test error, the concentrated mass elements simulating the accelerometers and the singlepoint spring element simulating the spring suspension were added in the FEM simulation, 
then the new FEM would be consistent with the actual test model, defined as G-FEM for convenience, while F-FEM represents the FEM simulation without the additional elements for structural dynamics and flutter analysis under free boundary, i.e., F-FEM was consistent with the free-free model without accelerometers and suspensions.

Table 4. Comparison of analysis results and GVT results.

\begin{tabular}{ccccc}
\hline \multirow{2}{*}{ Modal Name } & \multicolumn{4}{c}{ Modal Frequency (Hz) } \\
\cline { 2 - 5 } & GVT & G-FEM & Error & F-FEM \\
\hline Elastic heaving & 0.93 & 0.92 & $1.08 \%$ & $/$ \\
Symmetric 1st wing bending & 4.02 & 3.98 & $1.00 \%$ & 4.13 \\
Antisymmetric 1st wing bending & 7.12 & 6.98 & $1.97 \%$ & 7.20 \\
Symmetric 2nd wing bending & 8.87 & 8.73 & $1.58 \%$ & 8.92 \\
\hline
\end{tabular}

Based on the GVT results, G-FEM was updated, and the main updated parameter was Young's modulus of the CFRCM material, which was updated from 150 GPa to 109 GPa. The suspension spring stiffness was also tuned to match with the elastic heaving mode. The first four elastic mode shapes of the updated G-FEM are shown in Figure 15. The comparison between the results of updated FE and GVT simulations is summarized in Table 4. It can be seen that the first four elastic modes of the updated G-FEM match well with those of GVT, indicating that the updated G-FEM is in good agreement with the test results. The modal frequencies of the corresponding F-FEM are also listed in Table 4, which could be taken as the updated free-free modal results. Obviously, the spring stiffness and the mass of accelerometers affect the structural dynamic characteristics of the model.
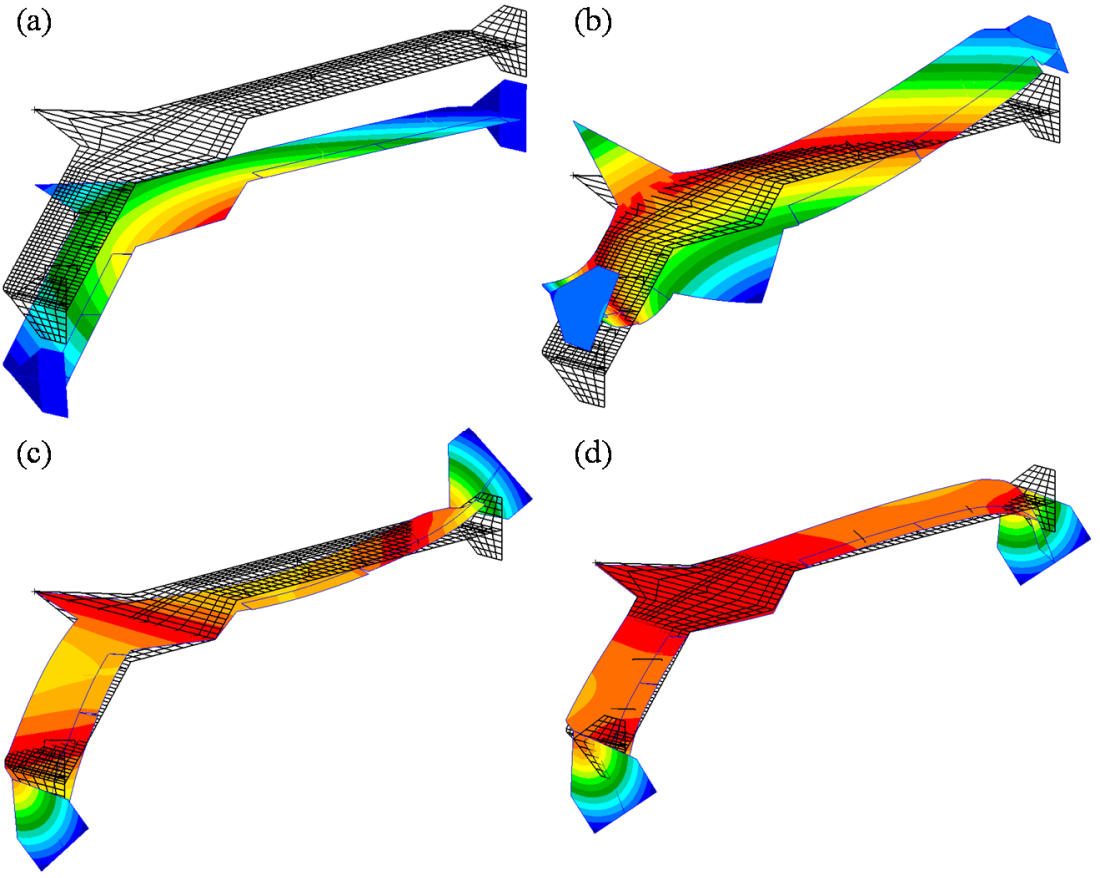

Figure 15. First four elastic mode shapes of G-FEM: (a) elastic heaving; (b) symmetric 1st wing bending; (c) antisymmetric 1st wing bending; (d) symmetric 2 nd wing bending.

The aeroelastic characteristics of the updated F-FEM were analyzed again by the g-method, and the obtained V $g$ and V-f curves are shown in Figure 16. It can be seen that the flutter speed and frequency of the updated F-FEM are $10.66 \mathrm{~m} / \mathrm{s}$ and $3.46 \mathrm{~Hz}$, respectively. The flutter speed of the updated F-FEM is much lower than that of the original FEM, which is beneficial to the flight test. 

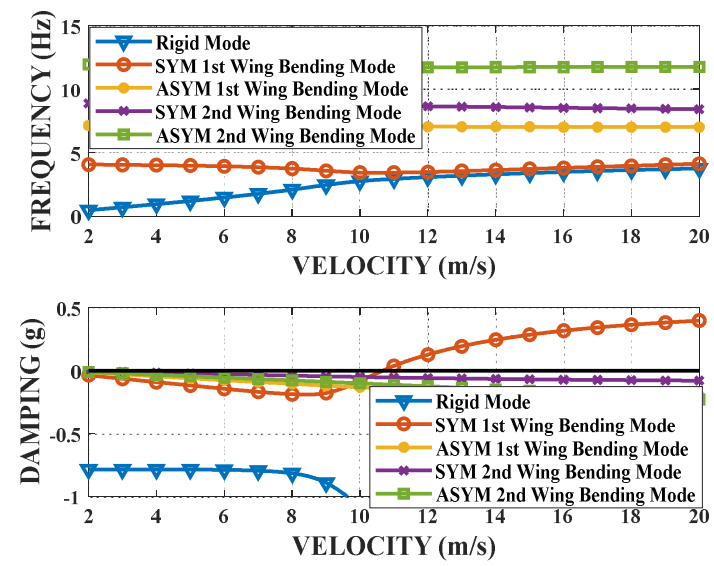

Figure 16. Aeroelastic characteristic of updated F-FEM.

\section{Flight Test}

The above results of simulations and GVT indicate the designed flying wing is feasible as a BFF flight test platform. The flight test was carried out at Northwestern Polytechnical University on a sunny day with a relatively stable atmospheric environment. The airborne acceleration sensor was used to collect the vertical acceleration response of the flying wing to record the vibration information during the flight test, and flutter characteristics were identified through the vertical acceleration signal. During the flight test, the flight speed was increased gradually, and the inner flap was deflected simultaneously to excite the test model. The BFF phenomenon was observed, as shown in Figure 17. The flying wing flew from the right to the left of the diagram. Due to the limited performance of our equipment, the photos were not very clear. However, the flutter mode is shown in the zoomed typical state in Figure 17; the pitch of the fuselage is marked with a blue line, and the symmetric bending of the wing is marked with a red line to facilitate observation. When approaching the critical speed of BFF, the flight altitude decreased rapidly. To protect the test model, immediately, the airspeed was reduced, and the test model was recovered from the state of BFF. After recovery, the test model could continue to maintain level flight and finally land smoothly. This test did not lead to the destruction of the test model.

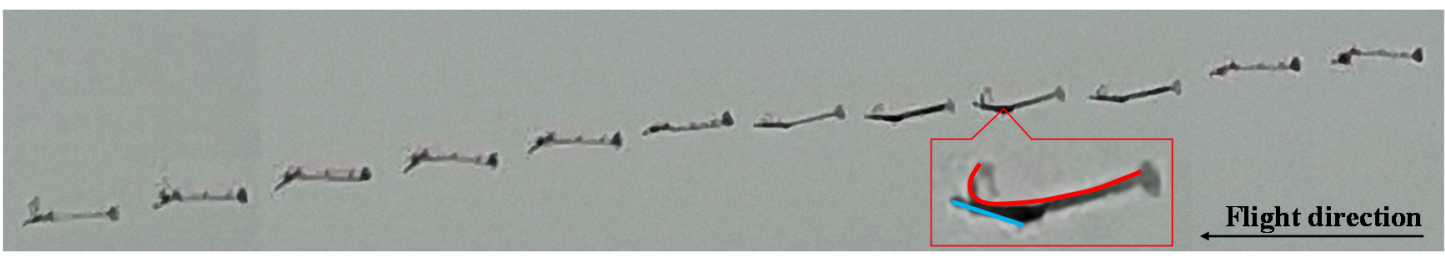

Figure 17. BFF occurred in flight test.

We carried out several BFF flight tests; the data of two representative experimental (named BFF\#1 and BFF\#2) are demonstrated in this paper, and the data of low-speed level flight are also given to compare with the BFF results. The experimental data include the flight velocity and vertical acceleration response information recorded by the airborne sensors. In order to check the frequency-domain information of the flight test, the frequency spectrum obtained by the fast Fourier transformation (FFT) of the time-domain acceleration signal is also plotted.

The flight test data of BFF\#1 is shown in Figure 18a. As can be seen from Figure 18a, the vertical acceleration response of the test model begins to diverge after the velocity of the test model reaches $12.03 \mathrm{~m} / \mathrm{s}$. The acceleration response converges when the flight velocity is lower than $11.86 \mathrm{~m} / \mathrm{s}$. Since the speed change is gentler in the acceleration process than that in the deceleration process, the BFF critical velocity is selected as $12.03 \mathrm{~m} / \mathrm{s}$ in BFF\#1. The frequency spectrum is shown in Figure 18b; there are three frequency response peaks 
occurring in the frequency range of $0 \sim 20 \mathrm{~Hz}$, and their frequencies are $3.13 \mathrm{~Hz}, 9.86 \mathrm{~Hz}$, and $16.41 \mathrm{~Hz}$, respectively. It should be noted that there might be a typical nonlinear characteristic shown in Figure 18b, as $9.86 \mathrm{~Hz}$ is almost 3 times (period 3) of $3.13 \mathrm{~Hz}$, $16.41 \mathrm{~Hz}$ is almost 5 times (period 5) of $3.13 \mathrm{~Hz}$, and $3.13 \mathrm{~Hz}$ (period 1) is the frequency of the flutter mode obtained from the flight test BFF\#1. Geometric nonlinearity is expected to arise due to the large deformation of the spar in flutter buildup, which might be a reasonable explanation for this kind of nonlinear flutter behavior.
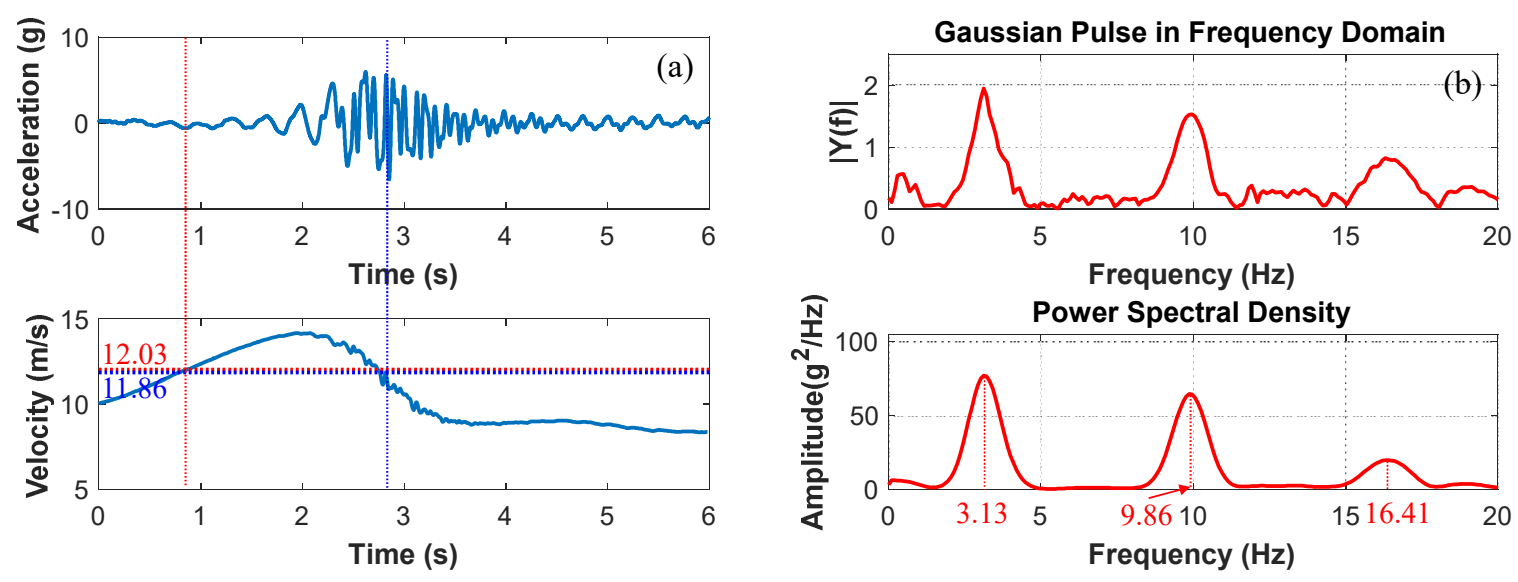

Figure 18. Flight test results of BFF\#1: (a) time-domain data and (b) frequency spectrum.

The vertical acceleration response and the velocity information of BFF\#2 are shown in Figure 19a, with the criteria for judging the flutter velocity in BFF\#1; the BFF critical velocity of BFF\#2 is $11.89 \mathrm{~m} / \mathrm{s}$. From the frequency spectrum of BFF\#2 shown in Figure 19b, we can see that there are three frequency response peaks occurring in the frequency range of $0 \sim 20 \mathrm{~Hz}$, and their frequencies are $3.13 \mathrm{~Hz}, 9.77 \mathrm{~Hz}$, and $16.21 \mathrm{~Hz}$, respectively. The amplitude of the response peaks with $3.13 \mathrm{~Hz}$ and $9.77 \mathrm{~Hz}$ is almost the same, which is the smallest for the $16.21 \mathrm{~Hz}$ frequency response peak, indicating that the nonlinear characteristic is more significant in BFF\#2, as flutter built up deeply. However, the fundamental frequency of the flutter mode in BFF\#2 is the same as that in BFF\#1.
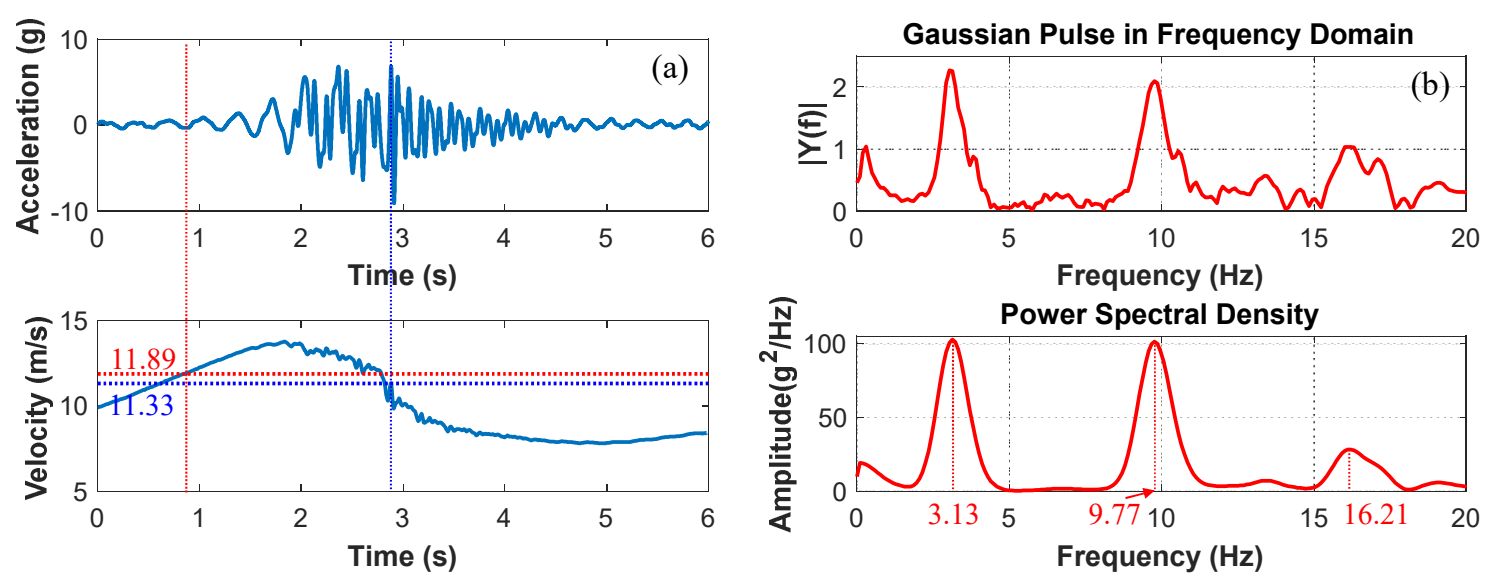

Figure 19. Flight test results of BFF\#2: (a) time-domain data and (b) frequency spectrum.

The flight test data of the low-speed level flight is shown in Figure 20a, according to which the flight velocity is almost $10 \mathrm{~m} / \mathrm{s}$, which is lower than the BFF critical velocity. The vertical acceleration response of the test model is calm. From the corresponding frequency spectrum shown in Figure 20b, we can hardly find any noticeable frequency response peak that corresponds to structural vibration mode with a frequency lower than $10 \mathrm{~Hz}$. 

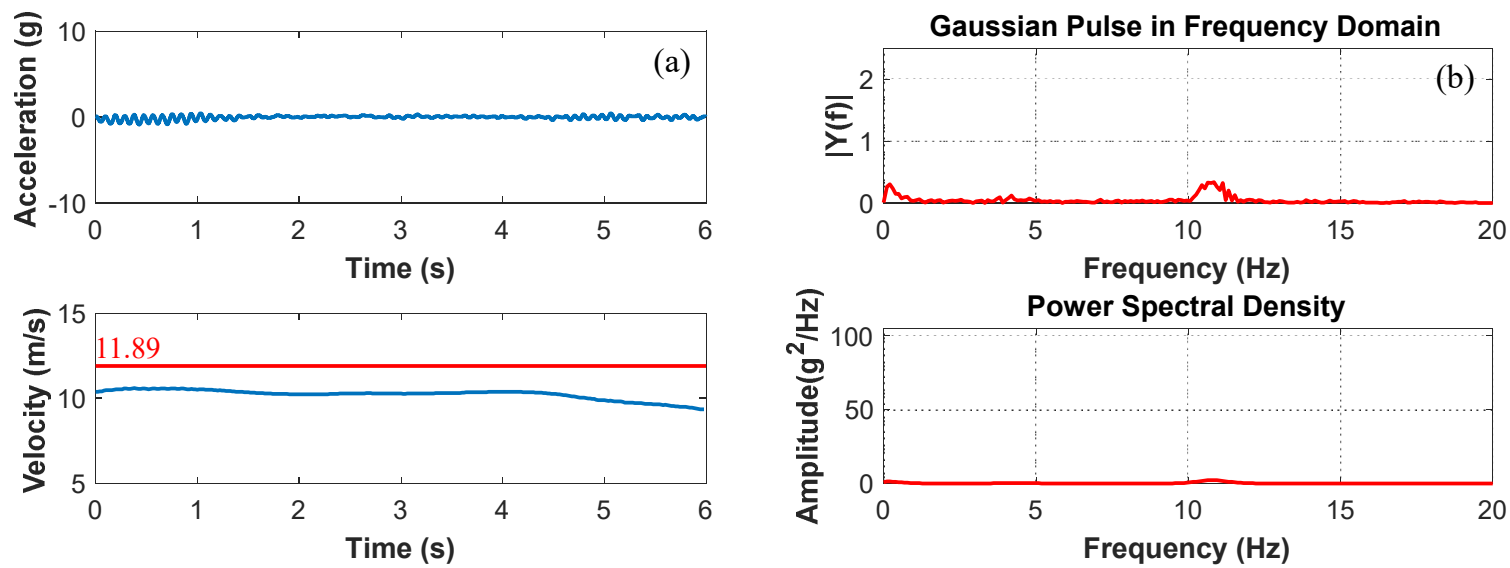

Figure 20. Flight test results of low-speed level flight: (a) time-domain data and (b) frequency spectrum.

The comparison between the results of the two effective flight tests and flutter analysis with $2 \%$ structural damping is summarized in Table 5 . The simulation results are in good agreement with those of the tests.

Table 5. Comparison of flight test results and analysis results with $2 \%$ structural damping.

\begin{tabular}{cccccc}
\hline Items & BFF\#1 & BFF\#2 & Analysis & Relative Error\#1 & Relative Error\#2 \\
\hline Flutter speed $(\mathrm{m} / \mathrm{s})$ & 12.03 & 11.89 & 10.82 & $10.06 \%$ & $9.00 \%$ \\
Flutter frequency $(\mathrm{Hz})$ & 3.13 & 3.13 & 3.46 & $10.54 \%$ & $10.54 \%$ \\
\hline
\end{tabular}

\section{Development of Active Flutter Suppression Controller}

As a potential active flutter suppression (AFS) testbed, the AFS study is also explored for the developed BWB BFF flight test research platform in this section. The AFS controller was designed in the framework of a closed-loop aeroservoelastic system for future tests. A genetic algorithm was applied, taking the position of the sensor as a design parameter in addition to the gains of the controller.

\subsection{Modeling of Closed-Loop Aeroservoelastic System}

A single-input-single-output (SISO) AFS controller, based on the proportional-integral (PI) feedback control law, was designed for the proposed flying wing. The schematic block diagram of the corresponding closed-loop aeroservoelastic system is shown in Figure 21. The input of the AFS controller was the vertical acceleration at the nose of the flying wing. A Butterworth filter was used to filter the output signal of the sensor, and the output signal of the controller was the deflection command of the actuator, which was used to drive the symmetric deflection of the ailerons of the flying wing and control the pitching motion of the vehicle, so as to achieve the flutter suppression.

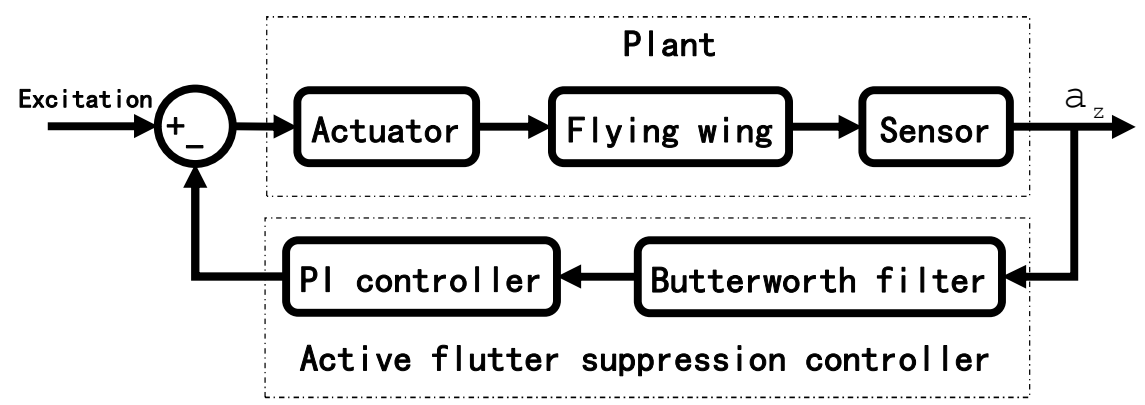

Figure 21. Schematic block diagram of closed-loop aeroservoelastic system. 
The closed-loop aeroservoelastic equation in the state-space form [22] is

$$
\begin{aligned}
& {\left[\begin{array}{c}
\dot{\mathbf{X}}_{p} \\
\dot{\mathbf{X}}_{k}
\end{array}\right]=\left[\begin{array}{cc}
\mathbf{A}_{p}+\mathbf{B}_{p} \mathbf{D}_{k} \mathbf{C}_{p} & \mathbf{B}_{p} \mathbf{C}_{k} \\
\mathbf{B}_{k} \mathbf{C}_{p} & \mathbf{A}_{k}
\end{array}\right]\left[\begin{array}{c}
\mathbf{X}_{p} \\
\mathbf{X}_{k}
\end{array}\right]+\left[\begin{array}{c}
\mathbf{B}_{p} \\
0
\end{array}\right] \mathbf{r}} \\
& \mathbf{Y}_{p}=\left[\begin{array}{ll}
\mathbf{C}_{p} & 0
\end{array}\right]\left[\begin{array}{c}
\mathbf{X}_{p} \\
\mathbf{X}_{k}
\end{array}\right]
\end{aligned}
$$

Let $\mathbf{A}_{v}=\left[\begin{array}{cc}\mathbf{A}_{p}+\mathbf{B}_{p} \mathbf{D}_{k} \mathbf{C}_{p} & \mathbf{B}_{p} \mathbf{C}_{k} \\ \mathbf{B}_{k} \mathbf{C}_{p} & \mathbf{A}_{k}\end{array}\right]$; the root locus of the closed-loop aeroservoelastic system can be obtained by solving the eigenvalues of $\mathbf{A}_{v}$ at different speeds. Similar to the open-loop case, the closed-loop critical flutter point can be determined according to the speed corresponding to the root locus crossing the imaginary axis.

\subsection{Design of the AFS System}

The PI controller was applied in the active flutter suppression system. The transfer function of the PI controller can be written as

$$
H(s)_{P I}=K_{P}+K_{I} * \frac{1}{s}
$$

where $K_{P}$ and $K_{I}$ represents the coefficients of proportional and integral links, respectively.

The negative flutter velocity of the closed-loop system was defined as the objective function, and the proportional coefficient $K_{P}$, integral coefficient $K_{I}$, and position of the sensor (using the serial number $L o c=1,2, \ldots, 5$, representing the 5 locations of the sensor as $0 \mathrm{~mm}, 100.68 \mathrm{~mm}, 200.86 \mathrm{~mm}, 316.53 \mathrm{~mm}, 380 \mathrm{~mm}$ at the nose, respectively) were selected as the genetic algorithm variables, i.e.,

$$
\left\{\begin{array}{c}
\min f(x)=-V_{f} \\
0.00001 \leq K_{P} \leq 0.01 \\
-0.01 \leq K_{I} \leq-0.00001 \\
1 \leq \text { Loc } \leq 5
\end{array}\right.
$$

where $V_{f}$ is the flutter velocity of the closed-loop system.

A genetic algorithm was used to solve this optimization problem. After 51 generations of iteration, the configuration of parameters with the best flutter suppression effectiveness was obtained within the defined range of variables. The convergence process of the objective function is shown in Figure 22.

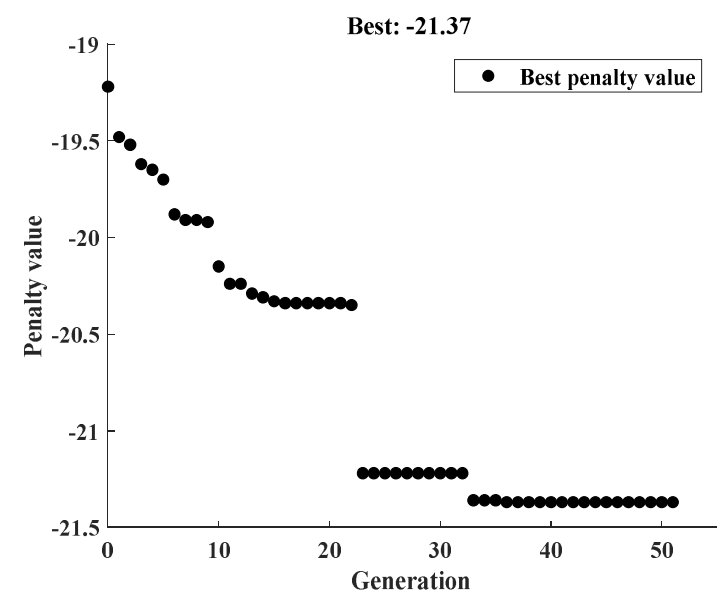

Figure 22. Genetic algorithm optimization process.

The corresponding parameters obtained from the genetic algorithm are summarized in Table 6. 
Table 6. Optimal configuration parameters of AFS.

\begin{tabular}{cc}
\hline Parameters & Values \\
\hline$L o c$ & $5(380 \mathrm{~mm}$ aft nose $)$ \\
$K_{P}$ & 0.00006 \\
$K_{I}$ & -0.00011 \\
\hline
\end{tabular}

The stability analysis of the closed-loop system with the optimal configuration parameters was carried out. The root locus diagram is shown in Figure 23a, and the results of the g-method are shown in Figure 23b. The results show that the closed-loop system is unstable at a speed of $21.37 \mathrm{~m} / \mathrm{s}$, and the corresponding flutter frequency is $9.53 \mathrm{~Hz}$. The flutter is caused by the coupling of antisymmetric first wing bending mode and antisymmetric second wing bending mode, which means that the flutter form is no longer BFF.

(a)

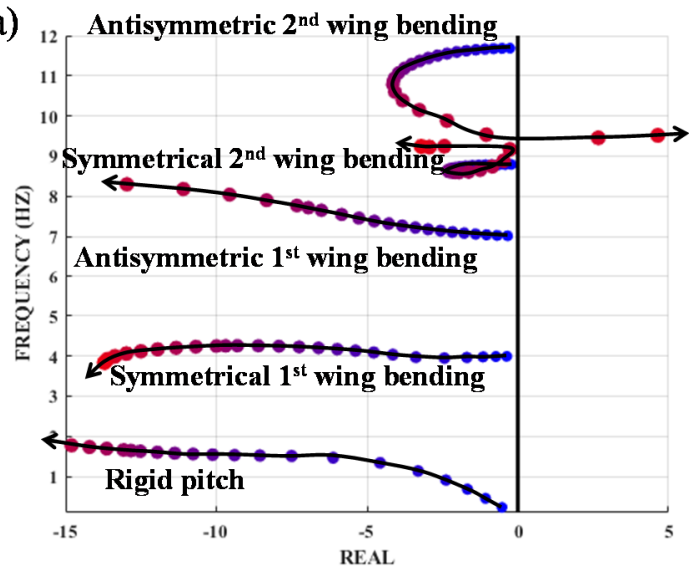

(b)
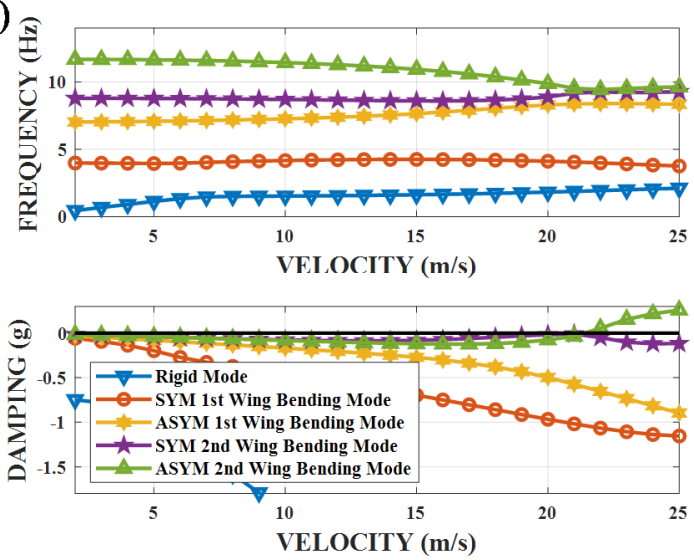

Figure 23. Stability of closed-loop system with optimal configuration parameters: (a) root locus diagram; (b) g-method results.

\section{Conclusions}

In this paper, the design and test process of an LCLR BWB flying wing, used as a BFF flight test platform, were introduced in detail. The design, processing, and manufacture of the test model were completed, and a GVT simulation was conducted to update the analysis model to be consistent with the test model. The classical BFF phenomenon at low speed was observed in the flight test, and the flutter characteristics were in good agreement with the updated analysis results, after which an AFS controller was designed for the developed flying wing for future tests. Compared with the analyses results of the open-loop system, the flutter boundary of the closed-loop system with the nominal parameters increased by $45.97 \%$, and that with the optimal configuration parameters increased by $100.47 \%$ after the genetic algorithm optimization. The instability form of the latter is no longer BFF.

Author Contributions: Data curation, P.S.; Formal analysis, P.S.; Supervision, Y.G. and Z.Y.; Writingoriginal draft, P.S.; Writing—review \& editing, F.L. and Y.G. All authors have read and agreed to the published version of the manuscript.

Funding: This research was financially supported by the National Natural Science Foundation of China (Grant No. 11672240, 11102162) and Natural Science Basic Research Plan in Shaanxi Province of China (Grant No. 2019JM-582).

Institutional Review Board Statement: Not applicable.

Informed Consent Statement: Not applicable.

Data Availability Statement: Sample data available on request.

Conflicts of Interest: The authors declare no conflict of interest. 


\section{Nomenclature}

$\begin{array}{ll}b & \text { Reference length } \\ \mathbf{D} & \text { Aerodynamic influence coefficient matrix } \\ \mathbf{G} & \text { Spline matrix } \\ k & \text { Reduced frequency } \\ \mathbf{K} & \text { Generalized stiffness matrix } \\ K_{i j} & \text { Aerodynamic kernel function } \\ K_{I} & \text { Coefficients of integral link } \\ K_{P} & \text { Coefficients of proportional link } \\ l & \text { Length at } 1 / 4 \text { chord } \\ \mathbf{M} & \text { Generalized mass matrix } \\ \mathbf{Q}(i k) & \text { Generalized aerodynamic influence matrix } \\ V_{f} & \text { Flutter velocity of the closed-loop system } \\ w & \text { Downwash at the } 3 / 4 \text { chord length point } \\ \mathbf{w} & \text { Downwash vector at the downwash control point } \\ \omega & \text { Circular frequency } \\ \phi & \text { Sweepback angle at } 1 / 4 \text { chord } \\ \mathbf{\Phi} & \text { Modal matrix } \\ \Delta c_{p} & \text { Pressure coefficient } \\ \Delta \mathbf{p} & \text { Pressure distribution vector } \\ \Delta x & \text { Midsection length }\end{array}$

$\begin{array}{ll}\text { Abbreviations } \\ \text { AFS } & \text { Active flutter suppression } \\ \text { BFF } & \text { Body freedom flutter } \\ \text { CFRCM } & \text { Carbon-fiber-reinforced composite material } \\ \text { DDT } & \text { Digital data transmission } \\ \text { DLM } & \text { Doublet lattice method } \\ \text { FE } & \text { Finite element } \\ \text { FEM } & \text { Finite element model } \\ \text { FFT } & \text { Fast Fourier transformation } \\ \text { GPS } & \text { Global positioning system } \\ \text { GVT } & \text { Ground vibration test } \\ \text { LCLR } & \text { Low cost and low risk } \\ \text { PI } & \text { Proportional integral } \\ \text { SISO } & \text { Single input-single output } \\ \text { UAV } & \text { Unmanned aerial vehicle } \\ \text { VLM } & \text { Vortex lattice method }\end{array}$

\section{References}

1. Wang, R.; Yan, M.; Bai, P. Optimization design of aerodynamics and stealth for a flying-wing UAV planform. Acta Aeronaut. Astronaut. Sin. 2017, 38, 73-80.

2. Pan, Y.; Huang, J.; Li, F.; Yan, C. Integrated Design Optimization of Aerodynamic and Stealthy Performance for Flying Wing Aircraft. In Proceedings of the Lecture Notes in Engineering and Computer Science, Hong Kong, China, 15-17 March 2017; Volume 2228, pp. 1051-1056.

3. Hainline, K.; Richter, J.; Agarwal, R.K. Vehicle Design Study of a Straight Flying-Wing with Bell Shaped Spanload. In Proceedings of the AIAA Scitech 2020 Forum, Orlando, FL, USA, 6-10 January 2020; p. 0007.

4. Zhang, S.; Wang, Z.-J.; Chen, H. The Dynamic Properties and Control Method of a Flying Wing with High Aspect-Ratio and Strong Coupling Between Aeroelasticity and Flight Dynamics. Trans. Beijing Inst. Technol. 2020, 40, 157-162.

5. Cheng, M.; Yuan, K.; He, H. Static Aeroelastic Effects on Rudder Efficiency of Flying Wing Aircraft. In Proceedings of the 2020 3rd International Conference on Unmanned Systems (ICUS), Harbin, China, 27-28 November 2020; pp. 727-732.

6. Jonsson, E.; Riso, C.; Lupp, C.A.; Cesnik, C.E.; Martins, J.R.; Epureanu, B.I. Flutter and post-flutter constraints in aircraft design optimization. Prog. Aerosp. Sci. 2019, 109, 100537. [CrossRef]

7. Cavallaro, R.; Bombardieri, R.; Demasi, L.; Iannelli, A. PrandtlPlane Joined Wing: Body freedom flutter, limit cycle oscillation and freeplay studies. J. Fluids Struct. 2015, 59, 57-84. [CrossRef] 
8. Liu, J.; Gu, Y.S.; Yang, Z.C. Influence of support stiffness on natural mode and body freedom flutter characteristics of a flying wing model. J. Vib. Eng. 2018, 31, 727-733.

9. Zhao, W.; Kapania, R.K. Bilevel Programming Weight Minimization of Composite Flying-Wing Aircraft with Curvilinear Spars and Ribs. AIAA J. 2019, 57, 2594-2608. [CrossRef]

10. Guo, S.; Jing, Z.W.; Li, H.; Lei, W.T.; He, Y.Y. Gust response and body freedom flutter of a flying-wing aircraft with a passive gust alleviation device. Aerosp. Sci. Technol. 2017, 70, 277-285. [CrossRef]

11. Schmidt, D.K.; Danowsky, B.P.; Kotikalpudi, A.; Theis, J.; Regan, C.D.; Seiler, P.J.; Kapania, R.K. Modeling, Design, and Flight Testing of Three Flutter Controllers for a Flying-Wing Drone. J. Aircr. 2020, 57, 615-634. [CrossRef]

12. Schmidt, D.K.; Danowsky, B.P.; Seiler, P.J.; Kapania, R.K. Flight-Dynamics and Flutter Analysis and Control of an MDAO-Designed Flying-Wing Research Drone. In Proceedings of the AIAA Scitech 2019 Forum, San Diego, CA, USA, 7-11 January 2019 ; p. 1816.

13. Zou, Q.; Mu, X.; Li, H.; Huang, R.; Hu, H. Robust Active Suppression for Body Freedom Flutter of a Flying-Wing Unmanned Aerial Vehicle. J. Frankl. Inst. 2021, 358, 2642-2660. [CrossRef]

14. Yang, Y.; Wang, X.; Zhu, J.; Yuan, X.; Zhang, X. Robust proportional incremental nonlinear dynamic inversion control of a flying-wing tailsitter. Proc. Inst. Mech. Eng. Part G J. Aerosp. Eng. 2020, 234, 2274-2295. [CrossRef]

15. Zhao, W.; Gupta, A.; Miglani, J.; Regan, C.D.; Kapania, R.K.; Seiler, P.J. Finite Element Model Updating of Composite Flying-wing Aircraft using Global/Local Optimization. In Proceedings of the AIAA Scitech 2019 Forum, San Diego, CA, USA, 7-11 January 2019; p. 1814.

16. Gu, Y.; Yang, Z.; Marzocca, P.; He, S. Body freedom flutter of a flexible blended wing body like plate-An experimental study. In Proceedings of the 17th International Forum on Aeroelasticity and Structural Dynamics (IFASD), Como, Italy, $25-28$ June 2017.

17. Liu, J.; Gu, Y.; Xie, K.; Shi, P. Flutter Modeling, Analysis and Test for Blended-Wing-Body Flying Wing. In Proceedings of the 2018 Asia-Pacific International Symposium on Aerospace Technology, Chengdu, China, 16-18 October 2018.

18. Zhang, Y.; Li, B.; Cui, P.; Zhou, N.; Wu, X. Numerical simulation of support interference characteristics on a low-aspect ratio flying-wing model. J. Phys. Conf. Ser. 2020, 1600, 012036. [CrossRef]

19. Wu, J.; Feng, S.; Wang, Y.; Shen, Y.; Bu, C. Support Interference Computations of Forced Oscillation Test for a Flying-Wing Dynamic Model. Asia-Pac. Int. Symp. Aerosp. Technol. 2018, 459, 346-360.

20. Rodden, W.P.; Taylor, P.F.; McIntosh, S., Jr. Further Refinement of the Subsonic Doublet-Lattice Method. J. Aircr. 1998, 35, 720-727. [CrossRef]

21. Dowell, E.H. A Modern Course in Aeroelasticity; Springer: Berlin/Heidelberg, Germany; Dordrecht, The Netherlands, 2005.

22. Chen, P.C. Damping Perturbation Method for Flutter Solution: The g-Method. AIAA J. 2000, 38, 1519-1524. [CrossRef]

23. Gavrilović, N.N.; Rašuo, B.P.; Dulikravich, G.S.; Parezanović, V. Commercial Aircraft Performance Improvement Using Winglets. FME Trans. 2015, 43, 1-8. [CrossRef] 